\title{
BMJ Open Evaluation of community pharmacists' readiness to implement the Falsified Medicines Directive (Directive 2011/62/ EC): an English cross-sectional survey with geospatial analysis
}

\author{
Ravina Barrett (10) 1,2
}

To cite: Barrett R. Evaluation of community pharmacists' readiness to implement the Falsified Medicines Directive (Directive 2011/62/EC): an English cross-sectional survey with geospatial analysis. BMJ Open 2020;10:e033405. doi:10.1136/ bmjopen-2019-033405

- Prepublication history and additional material for this paper are available online. To view these files, please visit the journal online (http://dx.doi. org/10.1136/bmjopen-2019033405).

Received 05 August 2019 Revised 04 December 2019 Accepted 10 December 2019

Check for updates

(C) Author(s) (or their employer(s)) 2020. Re-use permitted under CC BY-NC. No commercial re-use. See rights and permissions. Published by BMJ.

${ }^{1}$ School of Pharmacy and Biomolecular Sciences, University of Brighton, Brighton, UK

${ }^{2}$ School of Pharmacy and Biomedical Sciences, University of Portsmouth, Portsmouth, UK

Correspondence to

Mrs Ravina Barrett;

ravina.barrett@port.ac.uk

\section{ABSTRACT}

Objectives To evaluate the readiness to implement the Falsified Medicines Directive (FMD) by community pharmacies in England. Eight secondary objectives were assessed.

Setting Community/retail pharmacies.

Participants We invited pharmacists from 501

pharmacies to complete a survey. Non-contractors, non-pharmacists or pharmacists practising abroad were excluded. We randomly selected addresses, ensuring that they were nationally representative.

Interventions We mailed the survey in October 2018 with a single follow-up in January 2019. Respondents were invited to provide self-reported answers. A prepaid selfaddressed envelope was provided. We received favourable ethical approval.

Results 102 responses (20.44\% response rate) were received. Readiness to implement was poor: 4 (3.9\%) said very much, while 40 (39.2\%) said not at all and 29 $(28.4 \%)$ said not really. Increased workload and reduced profitability were anticipated, accompanied with improved patient safety. Prevalence of 'substandard and falsified (SF) medical products' was estimated at $1 \%-5 \%$, with erectile dysfunction at greatest risk of falsification. Different packaging would raise suspicions. Five (4.9\%) had identified SFs $(p<0.001$ one-sample binomial test). Of these, three $(2.9 \%)$ informed the medicines agency. None had been involved in any public health campaigns. Confidence and self-efficacy was low. Strategies to reduce SFs reaching the public are described. Pharmacist's role in combating SFs was elucidated. SFs were identified in deprived areas $4(9 \%)$ more often than in affluent areas 1 $(2 \%)$.

Conclusions Many pharmacies are not ready to implement FMD, potentially not capturing anticipated benefits of the directive, with greatest risk of harm in deprived area. We further validated a confidence scale. Limited public health campaigns may result in a lack of awareness among pharmacy professionals and patients. Limited awareness of technologies to identify falsified medicines exist, though further training is welcome. A worrying trend of under-reporting maybe prevalent. A larger sample study using this survey would be valuable.
Strengths and limitations of this study

- This is the first study to evaluate the readiness of community pharmacies in England to implement the European Union's Falsified Medicines Directive (Directive 2011/62/EC) by 9 February 2019.

- We invited pharmacists from 501 pharmacies across England to complete a survey.

- Postcodes of pharmacies were linked with freely available data on Index of Multiple Deprivation scores, which provides an estimate of the socioeconomic deprivation of the practice population.

- The interactive application helps to visualise the data easily: https://arcg.is/0q1mGf or https://portuni.maps.arcgis.com/apps/webappviewer/index. html?id=95497aeae0cf4411 abd8433d736b8989.

- Limitation of this study includes those inherent to surveys, particularly those dependent on retrospective recall.

\section{INTRODUCTION}

There is no universally agreed definition of counterfeit/falsified medication and jurisdictions around the world define these types of medicines in many different ways. WHO identifies 'substandard and falsified (SF) medical products $^{12}$ that demonstrate public harm. ${ }^{3}$ The European Union (EU) has a strong legal framework for the licensing, manufacturing and distribution of medicines supported by the EU member states in implementing the falsified medicines Directive. ${ }^{45}$ At writing, the UK remains an EU member state. At the end of the distribution chain, only licensed pharmacies and approved retailers are allowed to offer medicines for sale, including legitimate sale via the internet. ${ }^{67}$

No specific definition of counterfeit medical product exists within English law and the national competent agency (The Medicines and Healthcare products Regulatory 
Agency (MHRA)) adopts the definition contained within the European Falsified Medicines Directive (FMD) and has provided guidance on its implementation. The final part of the Directive, the 'safety features' Delegated Regulation (EU) 2016/161 comes into force on 9 February 2019 in the UK. ${ }^{8}$

This requires every prescription only medicine and some pharmacy medicines to be scanned at point of dispensing (to check against a central database that they are not falsified, recalled or expired) at community pharmacy level across the EU, before supplying to the patients. The pharmacists' responsibilities are to (1) check that the antitampering device placed on the package by the manufacturer is intact before dispensing and (2) scan the 2D barcode and communicating with the National Medicine Verification System to change the status of the pack from 'active' to 'inactive dispensed'. The first requires visual inspection while the second requires a scanning tool. ${ }^{9-11}$ This now forms a part of regulatory compliance inspections and can attract disciplinary actions against registered professionals and premises. ${ }^{12} 13$

Falsified medicines and medical devices are problematic in both primary and secondary care as they are not subject to the rigorous quality standards and can create difficulty in identifying sources of contamination and public harm. The parallel import system in the EU also permit legitimate movement of medicines through the supply chain over large geographical territories, which is susceptible to infiltration by SF medicines.

Pharmacist's ability to identify SF medication can help in thwarting public harm alongside implementation of the FMD. No studies of English pharmacist's experiences of implementing FMD exist. This study is needed because it seeks to understand the challenges faced by the healthcare team caring for National Health Service (NHS) patients and other under pressure models of care in the Western World. Challenges include growing patient demand, changing patterns of demand, insufficient funding in primary care, reduced access to general practitioners and addressing national health inequalities. From our 2016-2017 study, ${ }^{14}$ we hypothesise that the theme of 'lack of resources' may continue.

Preparing for FMD implementation is a fundamental, structural change in an already well-established pharmacy dispensing and checking processes that risk assesses and quality assures the core pharmacy business. Inserting an additional stage of 'FMD compliance checking' is intended to further risk reduce and safeguard the public.

Several change management theories exist ${ }^{15-21}$ for sustaining positive change. Rogers' Diffusion of Innovation Theory ${ }^{22}$ introduced five change phases: knowledge (education and communication to expose staff to the change), persuasion (use of change champions to pique staff interest; peers persuading peers), decision (staff decide whether to accept or reject the change), implementation (putting new processes into practice) and confirmation (staff recognise the value and benefits of the change and continue to use changed processes).
Change is inevitable in healthcare. A significant problem specific to healthcare is that almost two-thirds of all change projects fail for many reasons, such as poor planning, unmotivated staff, deficient communication or excessively frequent changes. ${ }^{23-25}$ The challenges relate to three features of their organisational environment: the fact that organisational change is mostly driven by external pressures; the speed with which change has to be implemented and the frequency of change initiatives. ${ }^{26}$

The lack of research evidence suggests that the change process, up to the point of the research period, was managed using a largely directive approach in the UK. However, FMD poses a national and Europe wide 'change process' that is at risk of failure for the reasons identified. Assessing the geographical progress of implementation (and SFs detection rates inherent there) may inform policy and prevent health inequalities from emerging, because of this legislation.

The current study on FMD implementation reflects how well the change process is fully characterised and supported by the many stakeholders, including retail pharmacy chains and employed pharmacists (especially financially in the workload and time allowance of the responsible staff). This includes the provision of additional resources (eg, computers, employee time, etc.), preparedness and ongoing provision of training, and managing any unexpected, unintended, consequences of such a change.

This highlights the need to describe current practices around identifying and reporting of SFs, so that in time, we may be able to describe the impact of FMD on pharmacy services and its effectiveness. We hypothesise that pharmacist's confidence of handling SFs may change over time and so, capturing a snapshot now may be useful as a benchmark. The study also gives voice to the pharmacy professionals who are expected to deliver the implementation, in a naturalistic environment (not previously done). These concepts link our primary and secondary objectives to provide a coherent rationale to our study objectives.

\section{Objectives}

The primary objective of this study was to evaluate the readiness to implement FMD (Directive 2011/62/EC) by 9 February 2019 by community pharmacies in England. Secondary objectives were to:

a. Assess the impact of change on current operations.

b. Establish prior knowledge of prevalence of $\mathrm{SF}$ medicines.

c. Determine what visual checks are done to identify SF medicines.

d. Establish current practice around the identification and reporting of SF medicines.

e. Establish current levels of awareness, involvement and training in public health by pharmacists with respect SF medicines.

f. Explore pharmacists confidence of handling SF medicines. 
g. Seek opinions on policy and understand the pharmacist's role in combating SF medicines.

h. Examine association with geospatial location and Index of Multiple Deprivation (IMD) scores.

\section{METHODS}

We invited pharmacists from 501 pharmacies that contribute to the NHS's Business Services Authority (BSA) dispensing data across England to complete a survey, as the BSA is responsible for pharmacy reimbursements and collates accurate prescription data on behalf of the NHS. Community pharmacies that are not NHS contractors, non-pharmacists or pharmacists practising abroad were excluded. Addresses were taken from publicly available BSA website (March 2018) to gain a nationally representative sample.

We selected them randomly between contractor code (FAQ87 to FYR36), which resulted in recruiting a single large national pharmacy chain. We ensured that they were nationally representative with respect to the number of prescription forms (invited sample mean 5355, SD 2044 versus English population mean 3564, SD 2692) and number of prescription items dispensed (invited sample mean 10817, SD 4611 vs English population mean 9875, SD 5480). This permits comparison with like for like businesses (approximately equal burden of work, similar team size and similar business complexity) across the country, therefore allowing fair comparison between pharmacies invited to study and the wider pharmacy population.

We mailed the cross-sectional survey in October 2018 with a single follow-up of non-responders in January 2019. Respondents were invited to provide self-reported answers. A prepaid self-addressed envelope was included. We sought and received favourable institutional ethical approval. No financial (or similar) benefits were offered to minimise biassed responses. ${ }^{27}$

\section{Questionnaire}

The questionnaire was composed of items relating to the objectives. The full survey is available in online supplementary appendix A. A previously validated scale $^{14}$ was incorporated in this survey.

We piloted the questionnaire via six steps. Questionnaire was pretested by researchers critically appraising the scale in a research-team focus group. This comprised two external practising community pharmacists, other academics with recent community and hospital practice experience, and student researchers. This allowed for detection and deletion of ambiguous words, misinterpretation of questions, poor questions and sensitive questions. Amendments and improvements were made to the format, structure and content. To improve internal validity and reliability, the survey instrument was piloted with another external community pharmacist, and cognitive testing (read aloud) was conducted. It took less than 10 min to complete the final survey.
There are 11619 community pharmacies in England in $2017-2018 .^{28}$ To be representative (assuming confidence level of $95 \%$, CI of $10 \%$, SE of $5 \%$, relative SE of $10 \%$ ), a minimum sample size of 95 was calculated. To achieve this, we invited 501 pharmacies as our previous response rates range between $15 \%$ and $25 \%$ in similar studies. ${ }^{142930}$ Analyses were undertaken using SPSS ${ }^{31}$ to present proportions, descriptive statistics and hypothesis testing at $95 \%$ confidence level and 5\% significance. Missing data are presented, and any subgroup analysis will be descriptive. Comments are thematically analysed. $^{32} 33$

Postcodes of pharmacies were linked with freely available data on IMD score, ${ }^{34}$ an estimate of the socioeconomic deprivation of the practice population and NHS dispensing data. ${ }^{35}$ The IMD is the official measure of relative deprivation for small areas in England and the latest scores are presented in IMD 2015 data. It is a composite score of seven underlying domains related to income deprivation, employment deprivation, education, skills and training deprivation, health deprivation and disability, crime, barriers to housing and services and living environment deprivation. ${ }^{34}$ We were interested to see if deprivation and SFs detection and reporting was linked in any way-which we find it is (as per our discussion and conclusion).

We mapped our results using ArcGIS online (https:// arcg.is/0q1mGf, legend: yellow dot, red dot and green dot represent those who are 'somewhat' and 'very much' ready to implement FMD by the 9 February 2019, who said FMD would affect workload and those who said FMD would affect business profitability, respectively. Orange dot represents those who had used the Yellow Card Scheme (YCS) for reporting SF, blue dot represents those who had ever identified SF and green dot represents all respondents). We created an app with several layers to visualise the data easily, freely and publically: https://portuni.maps.arcgis.com/apps/webappviewer $/$ index.html id=95497aeae 0 cf4411 abd8433d $736 b 8989$.

We mapped our responses alongside the IMD 2015 data (ranks: every postcode has a rank from 1 , which is the most deprived area up to 32844 that is the least deprived area. Deciles are published alongside ranks to assess relative deprivation and we have used these).

At the end of our survey, we included brief guidance on reporting counterfeit products via the YCS (https:// yellowcard.mhra.gov.uk/counterfeit-products/) operated by the MHRA. Participants can complete a two-page form to report a suspected counterfeit product (fake medicine or fake medical device) including any related side effects or safety concerns to the YCS. Participants can register on the site when submitting a report, or can register in advance. Alternatively, participants can report a suspected counterfeit anonymously by contacting the 24 hours counterfeit hotline telephone number on +44 (0)2030806701. 
Table 1 Characteristics of survey respondents $(n=102)$

Frequency (percentage \%;

Respondent variables $n=102$ )

\begin{tabular}{lc}
\hline Sex & \\
Male & $46(45.1 \%)$ \\
Female & $51(50.0 \%)$ \\
Preferred not to say & $5(4.9 \%)$ \\
Years of registration experience & \\
$0-5$ & $37(36.3 \%)$ \\
$6-10$ & $26(25.5 \%)$ \\
$11-15$ & $20(19.6 \%)$ \\
$16-20$ & $1(1.0 \%)$ \\
$>20$ years & $18(17.6 \%)$ \\
Working hours (per week) & \\
$16-24$ & $3(2.9 \%)$ \\
$25-34$ & $10(9.8 \%)$ \\
$35-44$ & $77(75.5 \%)$ \\
$45-54$ & $12(11.8 \%)$ \\
\hline
\end{tabular}

\section{No patient and public involvement}

We did not involve patients or the public in our work. This is likely to be done in the future.

We used the Strengthening the Reporting of Observational Studies in Epidemiology cross-sectional reporting guidelines. ${ }^{36}$

\section{RESULTS}

In total, 102 responses (20.44\% response rate) were received (two closures and abatements), satisfying our sample size needs. Demographic data are summarised in table 1.

Table 1 shows a sex ratio in line with the latest census. ${ }^{37}$ Most (62\%) responders had 10 years or less practice experience, with $75.5 \%$ working full-time hours. We enquired how ready respondents were to implement this directive. Forty (39.2\%) said not at all, 29 (28.4\%) said not really,

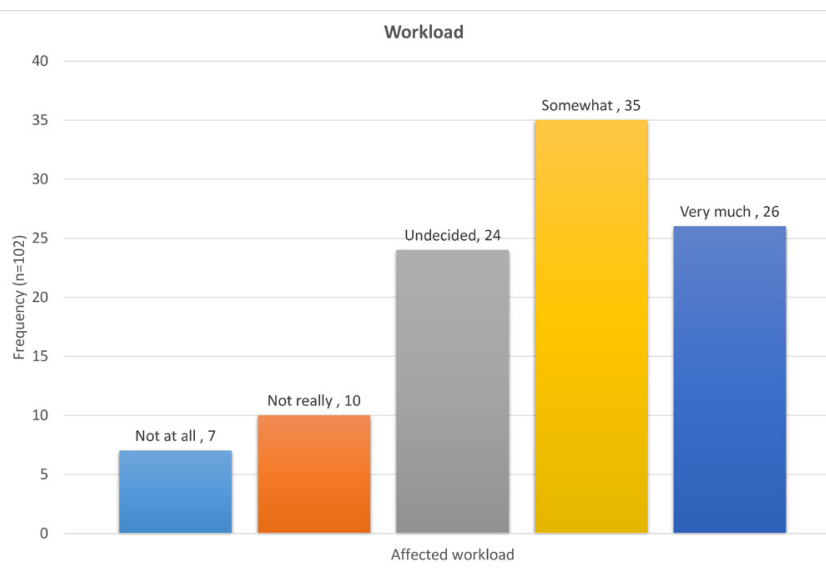

Figure 1 Impact on community pharmacy workload.

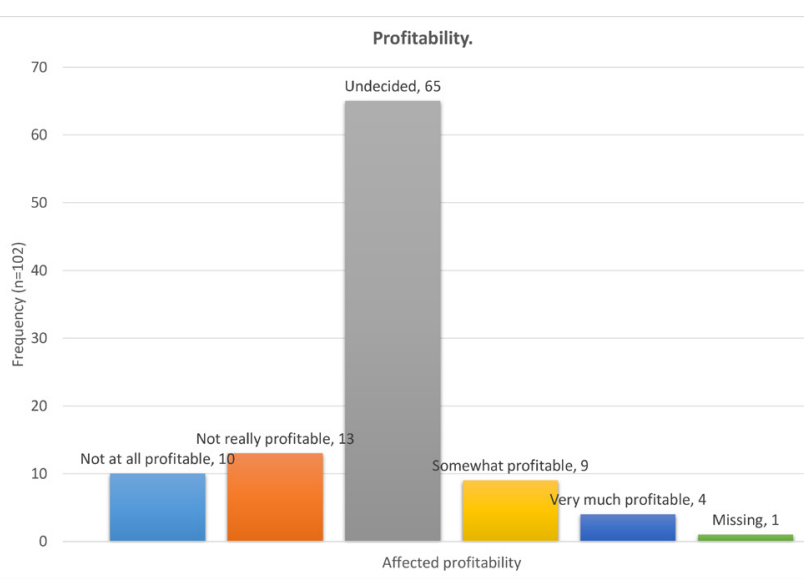

Figure 2 Impact on community pharmacy profitability.

$14(13.7 \%)$ were undecided, $12(11.8 \%)$ said somewhat and $4(3.9 \%)$ said very much, $3(2.9 \%)$ missing.

We enquired if adequate equipment and expenses were prepared (eg, computer terminals, scanners, compliance software, include initial set-up, IT, both software and hardware, plus ongoing operational costs). Twenty-two $(21.6 \%)$ said not at all, $26(25.5 \%)$ said not really, 12 $(11.8 \%)$ were undecided, $31(30.4 \%)$ said somewhat and $11(10.8 \%)$ said very much.

\section{Impact of change on current operations}

We perceived changes to workload and profitability, as shown in figures 1 and 2.

Improved patient safety is the desired outcome of this directive, so we enquired how this might be impacted (table 2).

\section{Prior knowledge of prevalence of SF medicines}

We wanted to know what percentage of medicines are believed to be falsified in the UK, as an indicator of prior knowledge of prevalence of SF medicines (see figures 3 and 4).

We asked about the most likely sources of falsified medicine: $59(56.2 \%)$ said 'internet pharmacies', 21 (20.0\%) said 'personal importation', 23 (21.9\%) said 'professional falsifier', 2 (1.9\%) said 'other' (of which 1 did not elaborate and another said 'including illegal websites'), 1 missing. Three respondents gave combination answers.

Finally, we asked what were the most commonly falsified medicines in the UK and invited multiple responses. Seven said 'anticholesterol', 5 said 'cancer', 77 said 'erectile dysfunction', 5 said 'heart problems', 32 said 'weight loss', 6 said 'other' (benzodiazepines, painkillers, anabolic steroids) and 2 missing.

\section{Visual checks done to identify SF medicines}

We asked what would raise suspicions of an SF. Forty said 'different distribution route', 40 said 'different labelling', 87 said 'different packaging to original packaging', 26 said 'different product composition' (eg, ingredients including excipients), 50 'different source' (eg, different manufacturer or country of origin) and 3 said 'other' 
Table 2 Impact on patient safety

\begin{tabular}{llllll}
\hline & $\begin{array}{l}\text { Does not improve } \\
\text { patient safety }\end{array}$ & $\begin{array}{l}\text { Does not improve } \\
\text { patient safety }\end{array}$ & Undecided & $\begin{array}{l}\text { Somewhat improves } \\
\text { patient safety }\end{array}$ & $\begin{array}{l}\text { Very much improves } \\
\text { patient safety }\end{array}$ \\
$\mathbf{N}(\%)$ & at all & $4(3.9 \%)$ & $14(13.7 \%)$ & $41(40.2 \%)$ & $38(37.3 \%)$ \\
\hline $\begin{array}{l}\text { Patient } \\
\text { safety }\end{array}$ & - & & & & \\
\hline
\end{tabular}

with reasons including cost, foreign text and medicine's appearance.

\section{Practice around the identification and reporting of SF medicines}

Five (4.9\%) had identified SF, 86 (84.3\%) had never, $11(10.8 \%)$ missing $(\mathrm{p}<0.001$ one-sample binomial test, $95 \%$ CI $1.95 \pm 0.0471)$. In such circumstance, three (2.9\%) informed the MHRA and five explanatory comments were received: 'Patient didn't want to report it she bought it from online pharmacy, I would contact MHRA' (not reported to MHRA). 'It was bought in by a patient who had bought it from a friend and wanted to check if it was genuine. Advised not to take' (not reported to MHRA). 'Referred patient back to where they purchased it' (not reported to MHRA). 'Yellow card'and 'Melatonin'were both reported to MHRA.

Twenty-one $(20.6 \%)$ kept records when encountering potential SF, $56(54.9 \%)$ did not, 25 (24.5\%) missing ( $<<0.001$ one-sample binomial test, 95\% CI $1.73 \pm 0.1$ ). Eight participants who kept records went on to elaborate with comments (major theme of recording and reporting): 'If we came across any on our (proprietary) system', 'Reporting on company system', 'Online reporting tools of pharmacy events', 'I would keep records', 'In store records', 'Hypothetically POM register, internal reporting system and Yellow card', 'Details of the medicine, Name, manufacturer, distributor, strength, form', 'Incident report sent online to headquarters'.

We enquired which national agency would they contact, if any. Nine said Department of Health, 17 said European Medicines Agency, 7 said Royal Pharmaceutical Society, 74 said MHRA, 15 said General Pharmaceutical Council and 3 said 'other', with reasons including 'Head office for

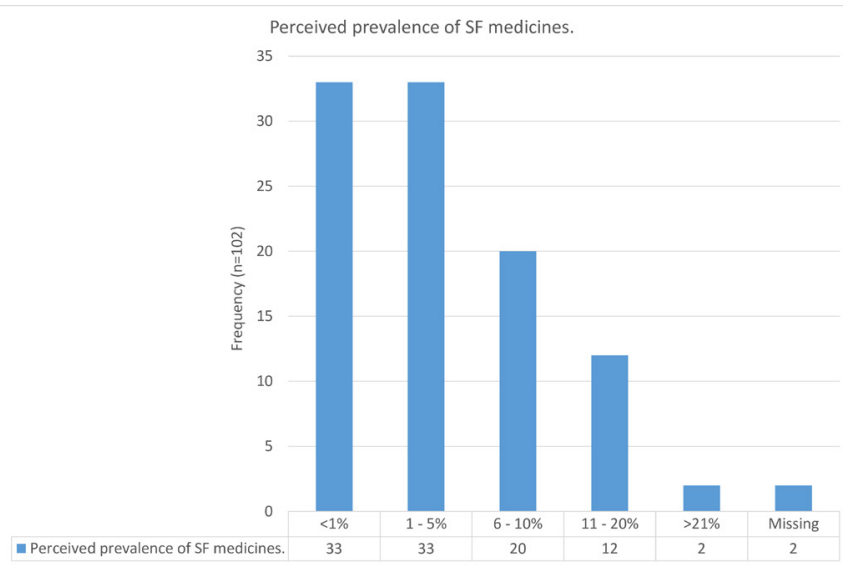

Figure 3 Perceived prevalence of substandard and falsified (SF) medicines. advice, then appropriate agency', 'company head office' and '[name] support office'.

Current awareness, involvement and training in public health None had been involved in any campaigns regarding SF, 91 (89.2\%) said no, and $11(10.8 \%)$ missing. No campaign was named, though, $8(7.8 \%)$ believed that the campaigns they encountered were effective, while $42(41.2 \%)$ did not, $52(51.0 \%)$ missing $(\mathrm{p}<0.001$ one-sample binomial test, $95 \%$ CI $1.91 \pm 0.121)$.

Six $(5.9 \%)$ had ever used the YCS for SF, $84(82.4 \%)$ had not, $12(11.8 \%)$ missing $(\mathrm{p}<0.001$ one-sample binomial test, $95 \%$ CI $1.93 \pm 0.0519)$. Thirty-seven $(36.3 \%)$ said yes this scheme is useful in combating SF, $34(33.3 \%)$ said no and $31(30.4 \%)$ missing.

To try and corroborate our findings to a nationally representative sample, we separately placed a freedom of information (FOI) request with the MHRA in October 2018 to request data regarding UK suspected adverse drug reactions (ADRs) that have been reported with suspected counterfeit or SF (query ref: GENQ-00131558). Where a patient has experienced a suspected ADR to a medicine, even if the medicine is suspected to be counterfeit or falsified, this is recorded on their database. The MHRA has received a total of $70 \mathrm{UK}$ spontaneous suspected ADR reports associated with SF for the period 1 July 1963-9 October 2018.

Three $(2.9 \%)$ had seen the 'Postcard Guidance for Patients ${ }^{38}$ leaflet, $88(86.3 \%)$ had not and $11(10.8 \%)$ missing $\quad(p<0.001$ one-sample binomial test, $95 \% \mathrm{CI}$ $1.97 \pm 0.037)$. Fourteen $(13.7 \%)$ were aware of technologies in place to identify SF, $76(74.5 \%)$ were not,

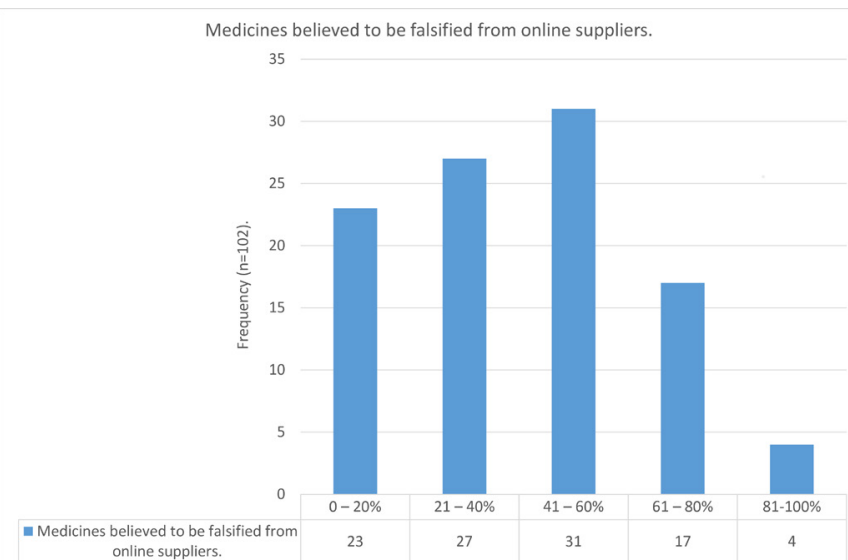

Figure 4 Medicines believed to be falsified from online suppliers. 


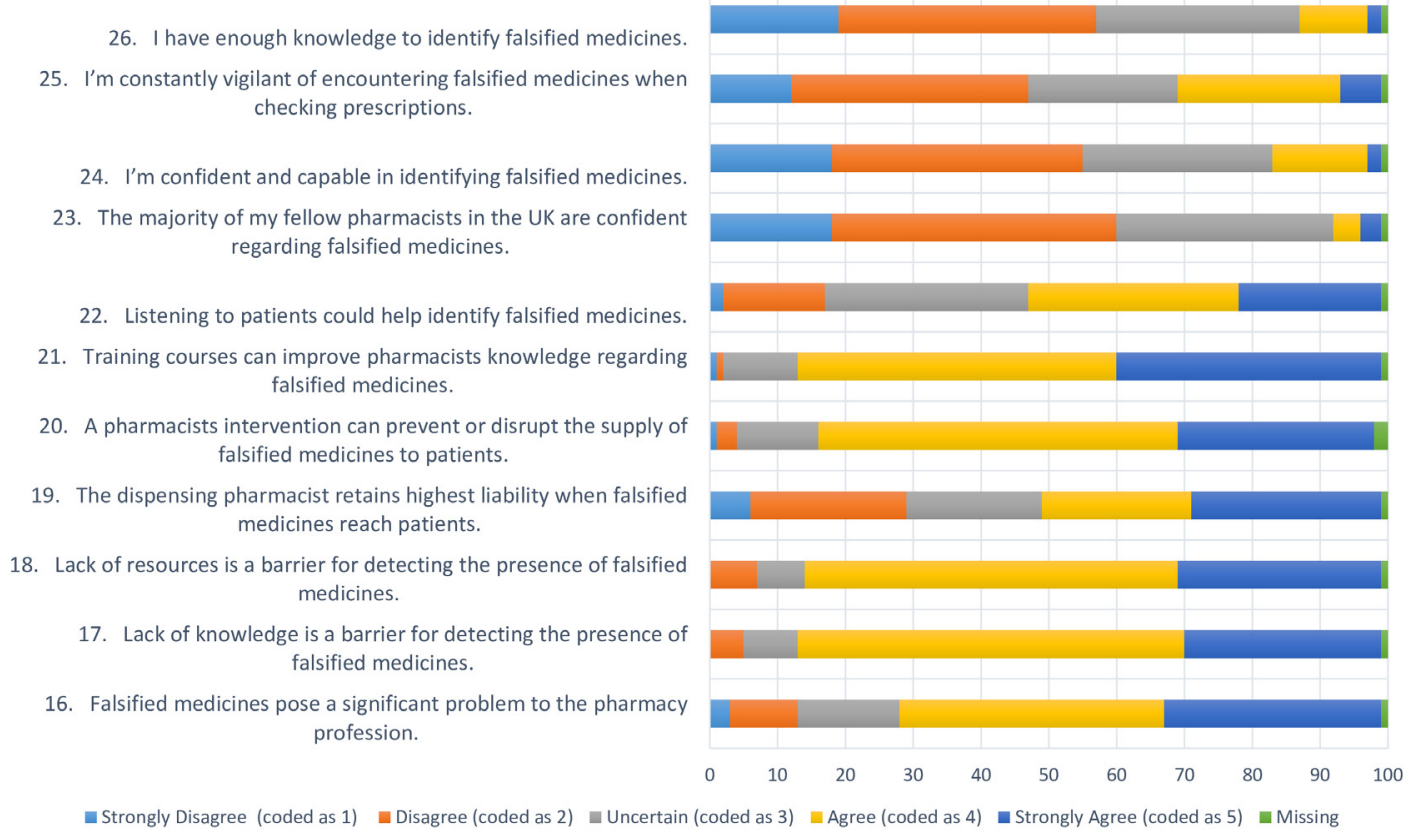

Figure 5 Confidence regarding handling falsified medicines ( $p<0.001$ one-sample $\chi^{2}$ test for all statements), percentages have been rounded to whole numbers. SF, substandard and falsified.

$12 \quad(11.8 \%)$ missing $\quad(\mathrm{p}<0.001$ one-sample binomial test, $95 \%$ CI $1.84 \pm 0.0752$ ). Technologies quoted in 11 comments presented two themes of barcode scanning and hologram use, and 91 missing. Thirty-six (35.3\%) believed that technologies were effective in combating SF, $28(27.5 \%)$ did not and $38(37.3 \%)$ missing. Three $(2.9 \%)$ had received any training regarding SF, $88(86.3 \%)$ had not and $11(10.8 \%)$ missing $(\mathrm{p}<0.001$ one-sample binomial test, 95\% CI $1.97 \pm 0.037)$. Seventy $(68.6 \%)$ would participate in such training, $13(12.7 \%)$ would not and $19(18.6 \%)$ missing $(\mathrm{p}<0.001$ one-sample binomial test, $95 \%$ CI $1.12 \pm 0.107)$.

\section{Confidence regarding handling SF medicines}

Then, we sought strength of opinion on a validated scale, ${ }^{14}$ presented in figure 5 . These cover statements 16-26 (online supplementary appendix A).

It is important to note that the scales was originally validated in a smaller sample $(\mathrm{n}=50)$ within Hampshire, UK. Validity and reliability are two fundamental elements in the evaluation of a measurement instrument. Validity is concerned with the extent to which an instrument measures what it is intended to measure. Reliability is concerned with the ability of an instrument to measure consistently. It should be noted that the reliability of an instrument is closely associated with its validity. An instrument cannot be valid unless it is reliable ${ }^{39}$ Cronbach's alpha is the most widely used objective measure of reliability. There are different reports about the acceptable values of alpha, ranging from 0.70 to 0.95 . $^{40-42}$

Previously, we reported a 0.728 Cronbach's alpha (on standardised items) of the 11 item (Q16-26) scale. ${ }^{14}$
Reliability statistics were recalculated here and a Cronbach's alpha (on standardised items) of the scale was 0.675 in this study ( $\mathrm{n}=100,2 \mathrm{missing}$ ). This is very close to 0.70 and we accept this sufficiently demonstrates validity. We did a further scale analysis with a Cronbach's alpha split-half in part 1 (the items are: Q16, Q17, Q18, Q19, Q20 and Q21.) and part 2 (the items are: Q22, Q23, Q24, Q25 and Q26.). We found the Cronbach's alpha for part 1 to be 0.672 , and for part 2 was 0.753 . The correlation between forms was 0.074 , the Spearman-Brown coefficient of equal and unequal length was 0.138 and the Guttman Split-half coefficient was 0.138, demonstrating good validity and reliability.

We have also presented current and previously validated means and SD to assess validity of our results and their relative difference (see online supplementary table 1 of appendix B), which shows small deviations from our original findings, except in statements 23, 25 and 26. Our study provides further face validity to this confidence scale, in a nationally representative sample.

\section{Opinions on policy and the pharmacists' role in combating SF medicines}

We enquired how we could reduce SF reaching the public. Forty-seven comments were received and present the following major and subthemes: (1) public health education, subtheme of (a) public education and (b) professional education (of all involved in supply chain); (2) (government) regulation and enforcement, subtheme of (a) regulated online sales and (b) regulatory control; (3) supply chain management, subtheme of (a) role of the manufacturers, (b) role of the wholesalers and (c) role of 
all (manufacturers, wholesalers and pharmacy); (4) serialisation (track and trace); and (5) reporting to the regulator, medical staff and internally to pharmacy. Detailed analysis is presented in online supplementary table 2 of appendix B.

We then asked what role can pharmacists play in combating falsified medicines. Thirty-seven comments were received with the major themes of (1) build into accuracy check; (2) complex and multifactorial; (3) education and training; (4) identify and report; (5) not pharmacist's role; (6) public awareness; (7) regulator's job; (8) reputable sources; (9) resources and (10) vigilance and action. Detailed analysis is presented in online supplementary table 3 of appendix B.

Five comments were additionally received (see online supplementary table 4 of appendix B) with major themes: (1) not a pharmacist's job; (2) quality supply chain; (3) technical difficulties; (4) wholesaler's duty; and (5) YCS ineffective.

\section{Examine geospatial location and IMD by decile}

We found that our sample was well distributed with good geographical representation of urban and rural residents, representing population densities fairly well: https:// arcg.is/0q1mGf. We stratified the data by decile (table 3 ) and visually assessed our maps. The data were segregated in near-even portions representing deprived areas versus affluent areas for easy comparison. With respect to inequalities, there seem to be minimal except for the detection rates of $\mathrm{SFs}$, which is higher in more deprived areas (see Q32a in online supplementary appendix C for details).

\section{DISCUSSION}

Most responders were not ready to implement FMD on the deadline, except four pharmacies and many did not know that this implementation was imminent.

\section{Impact of change on current operations}

FMD-related changes were perceived as disruptive to normal business flow and likely to negatively affect workloads (59.8\%). In turn, $22.5 \%$ perceived this to negatively impact profitability and $12.7 \%$ believes that it might increase profitability. Perhaps, some limitation of this survey question is that the participants were not themselves business owners, but employees within a larger business. We cautiously hypothesise that by their nature, they maybe more accurate at assessing impact to workload, but perhaps not to profitability. However, we do not know. Few $(3.9 \%)$ perceived this did not improve patient safety and $77.5 \%$ believes that it might improve patient safety. Improved patient safety is the main purpose of FMD, so it is interesting to note that more than $10 \%$ $(13.7 \%)$ of practitioners were undecided about this. This leads us to cautiously hypothesise that many participants believe the FMD adds more to the administrative burden, than improved patient safety.
Table 3 Respondent's demographics versus Index of Multiple Deprivation decile (1 poorest, 10 richest) distribution

\begin{tabular}{|c|c|c|}
\hline & $\begin{array}{l}\text { Deprived } \\
\text { decile (1-3) } \\
\mathrm{N}, \%\end{array}$ & $\begin{array}{l}\text { Affluent } \\
\text { decile (4-10) } \\
\mathrm{N}, \%\end{array}$ \\
\hline \multicolumn{3}{|c|}{ Frequency of respondents } \\
\hline $\mathrm{n}, \%$ & $50,100 \%$ & $52,100 \%$ \\
\hline \multicolumn{3}{|c|}{ Gender $(n=102)$} \\
\hline Male & $23,46 \%$ & $23,44 \%$ \\
\hline Female & $25,50 \%$ & $26,50 \%$ \\
\hline Other & $2,4 \%$ & $3,6 \%$ \\
\hline \multicolumn{3}{|c|}{$\begin{array}{l}\text { Years of registered } \\
\text { experience }(n=102)\end{array}$} \\
\hline $0-5$ & $17,34 \%$ & $20,38 \%$ \\
\hline $6-10$ & $11,22 \%$ & $15,29 \%$ \\
\hline $11-15$ & $11,22 \%$ & $9,17 \%$ \\
\hline $16-20$ & $1,2 \%$ & $0,0 \%$ \\
\hline$>20$ years & $10,20 \%$ & $8,15 \%$ \\
\hline \multicolumn{3}{|c|}{$\begin{array}{l}\text { Working hours per week } \\
(n=102)\end{array}$} \\
\hline $16-24$ & $1,2 \%$ & $2,4 \%$ \\
\hline $25-34$ & $8,16 \%$ & $2,4 \%$ \\
\hline $35-44$ & $32,64 \%$ & $45,87 \%$ \\
\hline $45-54$ & $9,18 \%$ & $3,6 \%$ \\
\hline
\end{tabular}

Ever used the YCS for SF

$(\mathrm{n}=90)$

\begin{tabular}{|c|c|c|}
\hline Yes & $3,7 \%$ & $3,7 \%$ \\
\hline No & $42,93 \%$ & $42,93 \%$ \\
\hline \multicolumn{3}{|c|}{$\begin{array}{l}\text { Seen the 'Postcard Guidance } \\
\text { for Patients' leaflet? }(n=91)\end{array}$} \\
\hline Yes & $1,2 \%$ & $2,4 \%$ \\
\hline No & $45,98 \%$ & $43,96 \%$ \\
\hline \multicolumn{3}{|c|}{$\begin{array}{l}\text { Aware of any technologies in } \\
\text { place to identify SF? }(n=90)\end{array}$} \\
\hline Yes & $6,13 \%$ & $8,18 \%$ \\
\hline No & $39,87 \%$ & $37,82 \%$ \\
\hline \multicolumn{3}{|c|}{$\begin{array}{l}\text { Ever received any training } \\
\text { regarding SF? }(n=91)\end{array}$} \\
\hline Yes & $2,4 \%$ & $1,2 \%$ \\
\hline No & $44,96 \%$ & $44,98 \%$ \\
\hline \multicolumn{3}{|c|}{ Ever identified SF? $(n=91)$} \\
\hline Yes & $4,9 \%$ & $1,2 \%$ \\
\hline No & $42,91 \%$ & $44,98 \%$ \\
\hline
\end{tabular}

Percentages (adjusted bases) have been rounded to whole numbers, small numbers may not add to $100 \%$.

SF, substandard and falsified; YCF, Yellow Card Scheme.

\section{Prior knowledge of prevalence of SF medicines}

There was unimodal distribution in the opinion of the percentage of medicines believed to be falsified in the UK, with a mode around $1 \%-5 \%$, which matches WHO 
estimates. ${ }^{3}$ Recent data show that the total number of items dispensed in 2017 was 1105.8 million. ${ }^{35}$ This represents $11.06-55.29$ million dispensed items that could be falsified, each with a potential to harm patients.

The percentage of medicines believed to be falsified from online suppliers, followed a near-normal distribution with a mode around $41 \%-60 \%$ from online suppliers. Responders believe the legitimate supply chain to be sufficiently protected, but have anxieties around online sources of medicines that are at a greater risk of falsification and may lead to greater public harm, which is supported by the wider literature. ${ }^{43-48}$ This phenomenon was supported in the answer around the most likely source of SF, which were identified as mainly originating from internet pharmacies. The most commonly falsified medicines in the UK was perceived to be erectile dysfunction product followed by weight loss medication.

\section{Visual checks are done to identify SF medicines}

Visual cues that would make pharmacists suspicious of a medicine being falsified included different packaging to the original packaging and a different source. The most commonly falsified medicines in the UK, their physical appearance and who to report it to were in line with the wider literature. $^{49} 50$

\section{Practice around the identification and reporting of SF medicines}

Off the five people who had identified SF, two reported it to the MHRA and three did not. Four were from deprived postcodes, whereas one was from an affluent area. While five is a very small number, we do not know the frequency at which they detected SFs. Five respondents represent $1 \%$ of the invited sample and $4.9 \%$ of all respondents. Upscaling these numbers to a national level would translate to 570 detections of SFs, without accounting for the cost of mitigating the damage to patients that may come from these SF medicines (while assuming: pharmacist detection of a single SF medicine, 11619 pharmacies nationally, $5 \%$ identified SFs). We also do not know if there is likely to be a cluster effect (isolated to a specific area) or a nationwide effect of these detections. These findings are internationally relevant because of similar globally reported trends in major developed economies. ${ }^{351}$

There seems to be a worrying practice of not reporting ADRs irrespective of point of purchase or local circumstance. This provides tentative support for our FOI request analysis, which indicates under-reporting of suspected ADRs related to SFs. Record keeping and ADR reporting are an essential and integral part of a pharmacist's duty. SF medicines pose an uncommon problem and so how professionals deal with this can be varied. However, more needs to be done to raise awareness of the need to report SF to the appropriate agency (ie, MHRA) and the importance of reporting related ADRs too. Reducing public harm is inherently acknowledged as key by responders.
Current awareness, involvement and training in public health Messages raising public awareness of SFs has not been reaching the public via pharmacy professionals, which raises important questions about promoting this message and getting it out to frontline staff and patients. While all pharmacy undergraduates are taught about the YCS in UK universities, this does not translate into practice as evidenced by general under-reporting ${ }^{52}$ of ADRs. Few respondents had reported SFs but more believed it helped to combat SFs. Six out of 501 of our respondents had reported SFs. Assuming our findings are nationally representative, we anticipate 140 reports. Therefore, the 70 reports lodged with the MHRA, we believe, indicate an under-reporting (see the Current awareness, involvement and training in public health section). This is supported in comments relating to informing the MHRA (see the Practice around the identification and reporting of SF medicines).

Only three respondents had seen the 'Postcard Guidance for Patients' leaflet, which conflicts with their earlier responses to involvement in any campaigns regarding SF but can be explained by prior training. A subgroup analysis of these three responders revealed that they were two women and one man, with $0-5$ years and $11-15$ years of practice experience, working 25-34hours and 35-44hours per week and all believed that FMD would greatly improve patient safety. All had received training regarding SF and all would further seek such training. While most respondents were not aware of technologies in place to identify SF, a handful could name some strategies in place and overall envisaged them having a limited impact in combating SFs. While most respondents did not receive training, $69 \%$ would participate in a training programme regarding SFs.

\section{Confidence regarding handling SF medicines}

Pharmacists accepted that SF medicines pose a significant problem and that their lack of knowledge and resources was potentially detrimental. They accepted a degree of liability in such circumstances and that their intervention could disrupt use of SF medicines. Further training and listening to the patients could be useful in overcoming these barriers. Low scores were generally given for self and peer group for confidence, capability, vigilance and knowledge levels.

Online supplementary appendix B table 1 shows slightly lower agreement in our sample with the statements: 'The majority of my fellow pharmacists in the UK are confident regarding falsified medicines', 'I'm constantly vigilant of encountering falsified medicines when checking prescriptions' and 'I have enough knowledge to identify falsified medicines'. This is normal and as expected because our sample is nearly double the original sample size. In this study, heterogeneous constructs or some missing data may have contributed to the lower value of Cronbach's alpha, but demonstrates criterion validity. 
Opinions on policy and the pharmacists' role in combating SF medicines

Strong opinions on policy surrounding public health education, regulation and enforcement, supply chain management, product serialisation and reporting were made, though a greater regulatory role and supply chain integrity are expected by pharmacists. The role of the pharmacist was to build these checks into their accuracy checking, encourage education and training, identify and report SF medicines, raise public awareness, source medicines from reputable sources, have adequate resources and be vigilant and act as necessary. Complex operational factors could make delivering all these difficult. Some respondents did not believe that this was part of the pharmacist role and that it was the regulators job.

\section{Examine geospatial location and IMD by decile}

We achieved a well-distributed sample, with good geographical representation. Analysing the data shows the following in deprived areas versus affluent counterparts: inadequate equipment $(22.9 \%$ vs $22.5 \%)$, lower knowledge (seen the 'Postcard Guidance for Patients' leaflet? (2\% vs $4 \%)$ ), unawareness of technologies $(87 \%$ vs $82 \%$ ), slightly higher rates of training ( $4 \%$ vs $2 \%$ ), higher rates of identifying SFs (9\% vs 2\%) (table 3 and online supplementary appendix $\mathrm{C}$ ), though none were statistically significant.

Service inequalities by location were minimal, except for the detection rates of SFs, which is surprising in a single organisational structure. These premises may require more resources, time and support to meet compliance standards. This subanalysis provides a snapshot of the deprivation landscape now and provides a benchmark for future evaluation to see if these pharmacies (and the communities they serve) get left behind.

\section{Strengths and limitations}

We report on a nationally representative sample in the first study of its kind, examining readiness to implement FMD by pharmacies in England. Limitation of this study include those inherent to surveys, particularly those dependent on retrospective recall.

To assess non-respondent bias, we examined dispensing statistics of the population, invited participants, respondents and non-respondents (table 4). Respondents tended to be from slightly busier pharmacies than nonrespondents, though by a small margin, making our findings nationally and internationally representative ${ }^{51}$ and generalisable.

\section{Future research}

A larger study using our survey would be valuable to further statistically validate our questionnaire (online supplementary appendix A) and we encourage the research community to use it to report their findings. The rollout of this implementation needs to be studied longitudinally to assess its full impact including on patient safety. Qualitative studies with participants that have (and have not)
Table 4 Bias assessment

\begin{tabular}{lll}
\hline $\begin{array}{l}\text { NHS dispensing monthly } \\
\text { (March 2018) statistics }\end{array}$ & $\begin{array}{l}\text { Number of } \\
\text { prescription } \\
\text { forms } \\
\text { (nominal) }\end{array}$ & $\begin{array}{l}\text { Number of } \\
\text { prescription } \\
\text { items } \\
\text { (nominal) }\end{array}$ \\
\hline $\begin{array}{l}\text { Mean } \\
\text { England population }\end{array}$ & 3564 & 7132 \\
\hline Invited & 5355 & 10817 \\
\hline Respondent & 5421 & 10953 \\
\hline Non-respondent & 5349 & 10800 \\
\hline SD & & \\
\hline England population & 2692 & 5167 \\
\hline Invited & 2044 & 4611 \\
\hline Respondent & 1918 & 4302 \\
\hline Non-respondent & 2077 & 4699 \\
\hline
\end{tabular}

identified and reported SFs may help explain why they reported it (or did not) and to explore ways of improving detection and reporting, to reduce public harm. More needs to be done about raising public awareness.

\section{CONCLUSIONS}

We find pharmacies are not ready to implement FMD and this remains an ongoing concern 9 months from implementation. ${ }^{12} 5455$ Impact on workload and profitability were areas of concern, though improved patient safety was anticipated. Of the total number of medicines dispensed in England, 1\%-5\% are believed to be falsified, with a greater proportion from online sources with erectile dysfunction and weight loss medicines at risk of falsification. Different packaging and different sources of medicine would raise suspicion among pharmacists. We found under-reporting of detected SF medicines, with low confidence and self-efficacy on SFs among pharmacists. Limited public health campaigns may result in a lack of awareness among pharmacy professionals and patients. Limited awareness of technologies in place identifying SFs exist, though further training is welcome. Policy changes in the area of public health education, regulation and enforcement, supply chain management, serialisation and reporting are important. Geospatial analysis revealed that more SFs were identified in deprived areas, potentially putting these patients at greater risk of harm from SF medicines and not capturing the full benefits of FMD implementation.

In conclusion, pharmacies are not FMD compliant and limited practical help and support seem available. A lack of resources, knowledge, competency, training and confidence make this a difficult directive to implement successfully. There is a risk that pharmacists maybe navigating this change in isolation, potentially coming to innovative workarounds to meet ongoing business targets with untold consequences. At a pharmacy-corporate level, sanctions for non-compliance maybe stressful, costly, 
time consuming and unattractive as these costs do not support business operations (or profitability) and maybe perceived as bureaucratic. Improved patient safety is anticipated, but difficult to quantify. Our study provides much needed data for evidence-based decision-making.

Acknowledgements Thank you to the 102 retail pharmacy respondent employees who took the time to provide honest opinions, Layla Mabood for helping with study administration and data collection, Michelle Sumner for providing excellent technical help to allow data capture and processing, and Martin Schaefer for his help with ArcGIS publisher requests.

Contributors The author conceived, designed, acquired, analysed and interpreted data. She developed and approved the version to be published and is accountable for its accuracy and integrity.

Funding The University of Portsmouth funded this study.

Disclaimer The views expressed in this publication are those of the author(s) and not those of the University of Brighton, University of Portsmouth, nor the NHS.

Competing interests None declared.

Patient consent for publication Not required.

Ethics approval University of Portsmouth, Science Faculty Ethics Committee provided a favourable ethical review (reference SFEC 2018-086, Date Submitted: 28 September 2018).

Provenance and peer review Not commissioned; externally peer reviewed. Data availability statement № data are available.

Open access This is an open access article distributed in accordance with the Creative Commons Attribution Non Commercial (CC BY-NC 4.0) license, which permits others to distribute, remix, adapt, build upon this work non-commercially, and license their derivative works on different terms, provided the original work is properly cited, appropriate credit is given, any changes made indicated, and the use is non-commercial. See: http://creativecommons.org/licenses/by-nc/4.0/.

ORCID iD

Ravina Barrett http://orcid.org/0000-0003-0004-2131

\section{REFERENCES}

1 World Health Organization. Definitions of substandard and Falsified (SF) medical products. Available: http://www.who.int/medicines/ regulation/ssffc/definitions/en/ [Accessed 27 Jun 2019].

2 World Health Organisation. Substandard and Falsified (SF) medical products. World health organ. Available: http://www.who.int/ medicines/regulation/ssffc/en/ [Accessed 27 Jun 2019].

3 World Health Organisation. Global surveillance and monitoring system for substandard and falsified medical products, 2017. Available: https://www.who.int/medicines/regulation/ssffc/ publications/GSMS_Report_layout.pdf?ua $=1$

4 European Commission. Directive 2011/62/EU of the European Parliament and of the Council of 8 June 2011 amending directive $2001 / 83 / E C$ on the community code relating to medicinal products for human use, as regards the prevention of the entry into the legal supply chain of falsified medicinal products text with EEA relevance. Available: http://eur-lex.europa.eu/legal-content/EN/TXT/?uri= celex\%3A32011L0062 [Accessed 27 Apr 2017].

5 Royal pharmaceutical Society | Falsified medicines directive. Available: http://www.rpharms.com/political-issues/falsifiedmedicines-directive.asp [Accessed 7 Mar 2017].

6 European Commission. Medicinal products for human use, Falsified medicines Public Health; 2013. https://ec.europa.eu/health/humanuse/falsified_medicines_en

7 European Commission. Falsified medicines Public Health; 2013.

8 Gov.UK. Guidance implementing the Falsified medicines directive: safety features, 2018. Available: https://www.gov.uk/guidance/ implementing-the-falsified-medicines-directive-safety-features [Accessed 27 Jun 2019].

9 Moore T. Falsified Medicines Directive: Safety Features - MHRA Inspectorate, 2019. Available: https://mhrainspectorate.blog.gov.uk/ 2019/02/08/falsified-medicines-directive-safety-features/ [Accessed 28 Nov 2019].

10 Burns C. Less than half of UK pharmacies will be ready for FMD The Pharmaceutical Journal; 2019.
11 Burns C. Pharmacy multiples to ensure FMD compliance 'as soon as practicably possible' The Pharmaceutical Journal; 2019.

12 Burns C. MHRA has taken action against companies on FMD compliance The Pharmaceutical Journal; 2019. https://www. pharmaceutical-journal.com/news-and-analysis/news/mhra-hastaken-action-against-companies-on-fmd-compliance/20206839. article

13 Burns C. FMD compliance to be part of pharmacy inspections The Pharmaceutical Journal; 2019: 302. https://www.pharmaceuticaljournal.com/news-and-analysis/news/fmd-compliance-to-be-part-ofpharmacy-inspections/20206022.article

14 Barrett R, Al-Mousawi HA. Development and initial validation of a postal survey evaluation of community pharmacists' opinion regarding falsified (counterfeit) medicines in Hampshire (UK) J Pharm Pharmacogn Res; 2018: 242-9.

15 Suc J, Prokosch H-U, Ganslandt T. Applicability of Lewin S change management model in a hospital setting. Methods Inf Med 2009;48:419-28.

16 Levasseur RE. People Skills: Change Management Tools-Lewin's Change Model. Interfaces 2001;31:71-3.

17 Shaqrah AA. Analyzing business intelligence systems based on 7S model of McKinsey. Int J Bus Intell Res 2018;9:53-63.

18 Pollack J, Pollack R. Using Kotter's Eight Stage Process to Manage an Organisational Change Program: Presentation and Practice. Syst Pract Action Res 2015;28:51-66.

19 Kosters M, Van der Heijden J. From mechanism to virtue: evaluating Nudge theory. Evaluation 2015;21:276-91.

20 Karambelkar M, Bhattacharya S. Onboarding is a change: applying change management model ADKAR to onboarding. Hum Resour Manag Int Dig 2017;25:5-8.

21 Hayes J. The theory and practice of change management. Fifth edition. London: Palgrave, 2018.

22 Moseley SF. Everett Rogers' diffusion of innovations theory: its utility and value in public health. $J$ Health Commun 2004:9:149-51.

23 Barrow JM, Toney-Butler TJ. Change Management. In: StatPearls. Treasure Island (FL): StatPearls Publishing, 2019. http://www.ncbi. nlm.nih.gov/books/NBK459380/

24 Lubitsh G, Doyle C, Valentine J. The impact of theory of constraints (TOC) in an NHS trust. J Manag Dev 2005;24:116-31.

25 Wankhade P, Brinkman J. The negative consequences of culture change management: evidence from a UK NHS ambulance service. Int J Public Sect Manag 2014;27:2-25.

26 Andrews J, Cameron H, Harris M. All change? managers' experience of organizational change in theory and practice. J Organ Change Manag 2008;21:300-14.

27 Cook JV, Dickinson HO, Eccles MP. Response rates in postal surveys of healthcare professionals between 1996 and 2005: an observational study. BMC Health Serv Res 2009;9:160.

28 NHS Digital. General Pharmaceutical Services in England 2007/2008 to 2017/2018. NHS Digit. Available: https://digital. nhs.uk/data-and-information/publications/statistical/generalpharmaceutical-services/in-england-2007-08-to-2017-18 [Accessed 27 Jun 2019].

29 Barrett R. Blood pressure monitor validation, calibration, and community pharmacy practice: a pilot cross-sectional survey in Hampshire, UK. Blood Press Monit 2018;23:281-2.

30 Barrett R, Costa D. An evaluation of community pharmacist perception of the misuse and abuse of over-the-counter co-codamol in cornwell and Devon, UK: a cross-sectional survey. Heroin Addict Relat Clin Probl 2018;20.

31 IBM Corp. IBM SPSS statistics for windows. Armonk, NY, 2014.

32 Braun V, Clarke V. Successful qualitative research: a practical guide for beginners. Los Angeles: SAGE, 2013.

33 Braun V, Clarke V. What can "thematic analysis" offer health and wellbeing researchers? Int J Qual Stud Health Well-being 2014;9:26152.

34 Ministry of Housing, Communities \& Local Government. English indices of deprivation 2015, 2015. Available: https://www.gov.uk/ government/statistics/english-indices-of-deprivation-2015 [Accessed 4 Mar 2019].

35 NHS Digital. Prescriptions dispensed in the community statistics for England, 2007-2017. NHS digit. Available: https://digital.nhs.uk/dataand-information/publications/statistical/prescriptions-dispensed-inthe-community/prescriptions-dispensed-in-the-community-england2007-2017 [Accessed 8 Mar 2019].

36 von Elm E, Altman DG, Egger M, et al. The strengthening the reporting of observational studies in epidemiology (STROBE) statement: guidelines for reporting observational studies. Int $J$ Surg 2014;12:1495-9.

37 Seston L, Hassell K. Pharmacy workforce census 2008: main findings. London, UK: Royal Pharmaceutical Society of Great 
Britain, 2009. www.rpharms.com/about-pharmacy-pdfs/census08. pdf

38 GOV.UK. Counterfeit medicines: what pharmacists should know. Available: https://www.gov.uk/drug-safety-update/counterfeitmedicines-what-pharmacists-should-know [Accessed 9 Nov 2018].

39 Tavakol M, Dennick R. Making sense of Cronbach's alpha. Int J Med Educ 2011;2:53-5.

40 Nunnally JC, Bernstein IH. Psychometric theory. 3rd. New York: McGraw-Hill, 1994.

41 Bland JM, Altman DG. Cronbach's alpha. BMJ 1997;314:572.

42 DeVellis RF. Scale development: theory and applications. Fourth edition. Los Angeles: SAGE, 2017.

43 Lundin S, Liu R. 'Where and how do you buy medicines?' A pilot survey of consumption strategies among the public in Sweden. $J$ Public Health;345.

44 Fantasia HC, Vooys KM. Public health implications of counterfeit medications. Nurs Womens Health 2018;22:264-8.

45 Mackey TK, Aung P, Liang BA. Illicit Internet availability of drugs subject to recall and patient safety consequences. Int J Clin Pharm 2015;37:1076-85.

46 El-Jardali F, AkI EA, Fadlallah R, et al. Interventions to combat or prevent drug counterfeiting: a systematic review. BMJ Open 2015:5:e006290.

47 Wang T, Hoag SW, Eng ML, et al. Quality of antiretroviral and opportunistic infection medications dispensed from developing countries and Internet pharmacies. J Clin Pharm Ther 2015;40:68-75.
48 Kimura M, Shimura S, Kobayashi $\mathrm{H}$, et al. Profiling characteristics of men who use phosphodiesterase type 5 inhibitors based on obtaining patterns: data from the nationwide Japanese population. $J$ Sex Med 2012;9:1649-58.

49 Dégardin K, Guillemain A, Klespe P, et al. Packaging analysis of counterfeit medicines. Forensic Sci Int 2018:291:144-57.

50 Chambliss WG, Carroll WA, Kennedy D, et al. Role of the pharmacist in preventing distribution of counterfeit medications. J Am Pharm Assoc 2012;52:195-9.

51 Merks P, Swieczkowski D, Byliniak M, et al. The European Falsified medicines directive in Poland: background, implementation and potential recommendations for pharmacists. Eur J Hosp Pharm 2018;25:10-15

52 Hazell L, Shakir SAW. Under-Reporting of adverse drug reactions. Drug Safety 2006;29:385-96.

53 Barrett R. Adverse-event management and reporting for electronic cigarettes (e-cigarettes). Eur J Hosp Pharm 2019;26:2-3

54 Stephen H. Just two Lloydspharmacy branches FMD compliant following it issues. Chemist+Druggist, 2019. Available: https://www. chemistanddruggist.co.uk/news/just-two-lloydspharmacies-fmdcompliant-following-it-issues [Accessed 25 Nov 2019].

55 Moore T. How the implementation of Safety Features progresses 5 months in - MHRA Inspectorate, 2019. Available: https:// mhrainspectorate.blog.gov.uk/2019/07/05/how-the-implementationof-safety-features-progresses-5-months-in/ [Accessed 25 Nov 2019]. 